\title{
Synthesis and characterization of cationic lipid coated magnetic nanoparticles using multiple emulsions as microreactors
}

\author{
Hasan Akbaba ${ }^{\mathrm{a}}$, Uğur Karagöz ${ }^{\mathrm{a}}$, Yusuf Selamet ${ }^{\mathrm{b}, 1}$, A. Gülten Kantarcı ${ }^{\mathrm{a}, *}$ \\ a Ege University, Faculty of Pharmacy, Department of Pharmaceutical Biotechnology, 35100 Izmir, Turkey \\ b Izmir Institute of Technology, Faculty of Science, Department of Physics, 35433 Izmir, Turkey
}

\section{A R T I C L E I N F O}

\section{Keywords:}

Cationic magnetic nanoparticle

Multiple emulsion

In-situ lipid coating

Microreactor

\begin{abstract}
A B S T R A C T
The aim of this study was to develop a novel iron oxide nanoparticle synthesis method with in-situ surface coating. For this purpose multiple emulsions were used as microreactors for the first time and magnetic iron oxide particles synthesized in the core of cationic solid lipid nanoparticles. DLS, SEM, TEM, VSM, Raman Spectrometer, XRD, and XPS techniques were performed for characterization of the magnetic nanoparticles. Obtained magnetic nanoparticles are superparamagnetic and no additional process was needed for surface adjustments. They are positively charged as a result of cationic lipid coating and has appropriate particle size ( < $30 \mathrm{~nm}$ ) for drug or nucleic acid delivery. Structure analysis showed that magnetic core material is in the form of magnetite. Saturation magnetization value was measured as $15-17 \mathrm{emu} \mathrm{g}^{-1}$ for lipid coated magnetic nanoparticles obtained by multiple emulsion method which is reasonably sufficient for magnetic targeting.
\end{abstract}

\section{Introduction}

In order to carry genetic materials or drugs for clinical uses, efficacious, targetable and highly reliable transport systems are needed [1-3]. Delivery of drugs or genes to the target under a magnetic field is one of the promising delivery method both in vitro and in vivo $[4,5]$. Iron oxide nanoparticles can be used for this purpose. The main problems in producing magnetic iron oxide $\left(\mathrm{Fe}_{\mathrm{n}} \mathrm{O}_{\mathrm{m}}\right)$ nanoparticles are the low magnetization values and the wide range of particle size distribution. Such delivery systems also need a biocompatible, nontoxic surface coating for loading drugs, to form complexes with nucleic acids and increasing bioavailability in the organism [3,6-8].

As to the previous data, synthesis of iron oxide nanoparticles by coprecipitation method is the simplest and most widely used method. In this method magnetic nanoparticles (MNPs) synthesized by precipitating aqueous solutions of $\mathrm{Fe}^{+2}$ and $\mathrm{Fe}^{+3}$ ions using a base as hydroxylation agent. However, this method has some disadvantages about particle shape control, particle size distribution and particle aggregation [9-13].

Obtaining of MNPs using the microemulsion technique is another method [13-18]. Considerably small nanoparticles which are appropriate for in vivo applications can be obtained by this method. Further, the particle size distribution is also quite homogeneous. Simple mixtures of water/oil microemulsions to obtain MNPs can be given as examples of this method. While one of such microemulsions contains a metallic salt or mixtures of iron oxide compounds, the other one carries the reducing agent. Due to their small particle size, the microemulsion droplets exhibit Brownian motion and hence they form a colloidal state. During these movements momentary dimers or aggregates are formed, ensuring exchanges between the microemulsion inner phases and chemical reaction takes place to form MNPs [19-21].

One of the significant problem encountered in the synthesis of MNPs with iron compounds is the tendency of the reaction to synthesize non-magnetic iron compounds. This is mainly caused as a result of the effect of dissolved oxygen in the solutions. The dissolved oxygen must therefore be removed from the medium. The removal is performed by creating a nitrogen gas environment $[18,22]$. Maintaining $\mathrm{pH}$ of the medium in the acidic range is another solution [23]. For the multiple emulsion method that we prepared, solutions of $\mathrm{Fe}^{+2}$ and $\mathrm{Fe}^{+3}$ are in the form of droplets surrounded by a lipid layer of water/oil microemulsion. In this situation, the rate of contact with the external environment or with atmospheric oxygen is lower. Another point is that the lipids participating in the microemulsion composition exert a protective effect by reducing the $\mathrm{pH}$ level, since they contain fatty acids. Briefly, in this work we developed a novel magnetic nanoparticle synthesis method with an appropriate particle size, zeta potential, and sufficient magnetic property for nucleic acid and drug targeting by combining advantages of microemulsion and multiple

\footnotetext{
* Corresponding author.

E-mail address: gulten.kantarci@ege.edu.tr (A.G. Kantarcı).

${ }^{1}$ Deceased on August 5, 2016.
} 
emulsion methods.

\section{Experimental}

\subsection{MNP Synthesis}

To obtain triangular phase diagram of water in oil (w/o) microemulsion is the first step of synthesis method. Microemulsions were formed with glyceryl monostearate as oil phase, Span 80 as non-ionic surfactant, ethanol as co-surfactant and $\mathrm{Fe}^{+2}$ and $\mathrm{Fe}^{+3}$ ionic solutions as water phase $\left(\mathbf{w}_{\mathbf{1}} / \mathrm{o}\right)$ over the lipid melting point. Dimethyldioctadecylammonium bromide (DDAB) was used for adding cationic property to the MNPs. Surfactant and co-surfactant were mixed and brought to a temperature $10{ }^{\circ} \mathrm{C}$ higher than the melting temperature of the solid lipids. Then, the mixture was titrated with the water phase, at this temperature, until turbidity occurs and transparent regions belongs to $\mathrm{w} / \mathrm{o}$ microemulsion area in triangular phase diagram was defined. A formulation which has the largest volume of inner water phase was selected from this transparent area. Selected microemulsion was used as an interior emulsion of multiple emulsions $\left(\mathbf{w}_{\mathbf{1}} / \mathbf{o} / \mathrm{w}_{2}\right)$, Tween 80 was used as an outer hydrophilic surfactant and ultra-pure water used as an outer water phase $\left(\mathrm{w}_{1} / \mathrm{o} / \mathbf{w}_{\mathbf{2}}\right)$. Afterwards $2 \mathrm{~N} \mathrm{NH}{ }_{4} \mathrm{OH}$ was used to increase $\mathrm{pH}$ of the system. $\left[\mathrm{OH}^{-}\right]$ions were leaked to the interior water phase of the multiple emulsion and reaction occurred between $\left(1 \mathrm{M} \mathrm{Fe}^{+2}\right)$ and $\left(2 \mathrm{M} \mathrm{Fe}^{+3}\right)$ solutions [24]. Magnetic iron oxide particles were synthesized in the core of cationic lipids.

$1 \mathrm{~mL}$ of hot multiple emulsions with magnetic core was taken in a pre-heated injector and dropped into the ice-cold distilled water. MNPs were formed when hot multiple emulsion droplets met with cold water [25-27]. MNPs were collected by using a neodium magnet and washed twice with distilled water and the characterization studies were carried on (Fig. 1) [12].

To understand the effects of formulation on magnetization and magnetic core material, one formulation (NP- $\varnothing$ ) was prepared with the same way as described above, and instead of $\left(1 \mathrm{M} \mathrm{Fe}^{+2}\right)$ and $\left(2 \mathrm{M} \mathrm{Fe}^{+3}\right)$ solutions only ultra-pure water was used in the interior water phase of multiple emulsions $\left(\mathbf{w}_{\mathbf{3}} / \mathrm{o} / \mathrm{w}_{2}\right)$.

\subsection{Measurements}

Dynamic light scattering (DLS) measurements were performed to determine particle size of MNPs at $25^{\circ} \mathrm{C}$ using a Zetasizer Nano ZS (Malvern, UK).

Magnetic properties of nanoparticles were characterized using Vibrating Sample Magnetometer (VSM) (Lakeshore, USA). MNPs were also synthesized by a well-known co-precipitation method (MNP-CoP) with the same external conditions to compare the magnetization degree of MNPs obtained by multiple emulsions method (MNP-MuE).

The morphology of MNPs was visualized by using Transmission Electron Microscope (TEM) and Scanning Electron Microscope (SEM). For these measurements a drop of diluted MNPs was placed on a TEM grid, allowed to dry in air and visualized.

Confocal Raman scattering measurements were performed on lyophilized MNP powders with Raman spectrometer (Princeton Instruments) equipped with a $\mathrm{He}-\mathrm{Ne}$ laser source giving an excitation wavelength of $633 \mathrm{~nm}$ and/or $\mathrm{Ar}^{+}$laser source giving an excitation wavelength of $488 \mathrm{~nm}$. The laser was focused using a 100x objective and Raman scattering was recorded using a 150 and 600 groves $/ \mathrm{mm}$ gratings. Characteristic peaks related to magnetic components in the samples were normalized and identified.

For the X-ray diffraction (XRD) and X-ray photoelectron spectroscopy (XPS) analysis, MNP suspensions were dropped onto cover slips and were allowed to dry under $\mathrm{N}_{2}$ atmosphere. XRD measurements were collected with Phillips X'Pert Pro X-ray diffractometer operated at $50 \mathrm{kV}$ and $50 \mathrm{~mA}$ with monochromatic $\mathrm{Cu}-\mathrm{Ka}$ radiation $(\lambda=0.15406 \mathrm{~nm})$ at scan range of $10^{\circ}<2 \theta<80^{\circ}$. XPS spectrum was recorded on Thermo Scientific K-Alpha System with monochromatic $\mathrm{Al}-\mathrm{Ka}$ radiation $(\lambda=1486.6 \mathrm{eV})$ with pass energy of $50 \mathrm{eV}$ as the X-ray source. XPS spectra were measured in $1.0 \mathrm{eV}$ intervals within 1361 energy steps. A broad scan of all components, and expanded scans of iron and nitrogen ions were collected. XPS mass percentages of the surface elements were calculated.

\section{Results and discussion}

The most widely used method for magnetic nanoparticle production

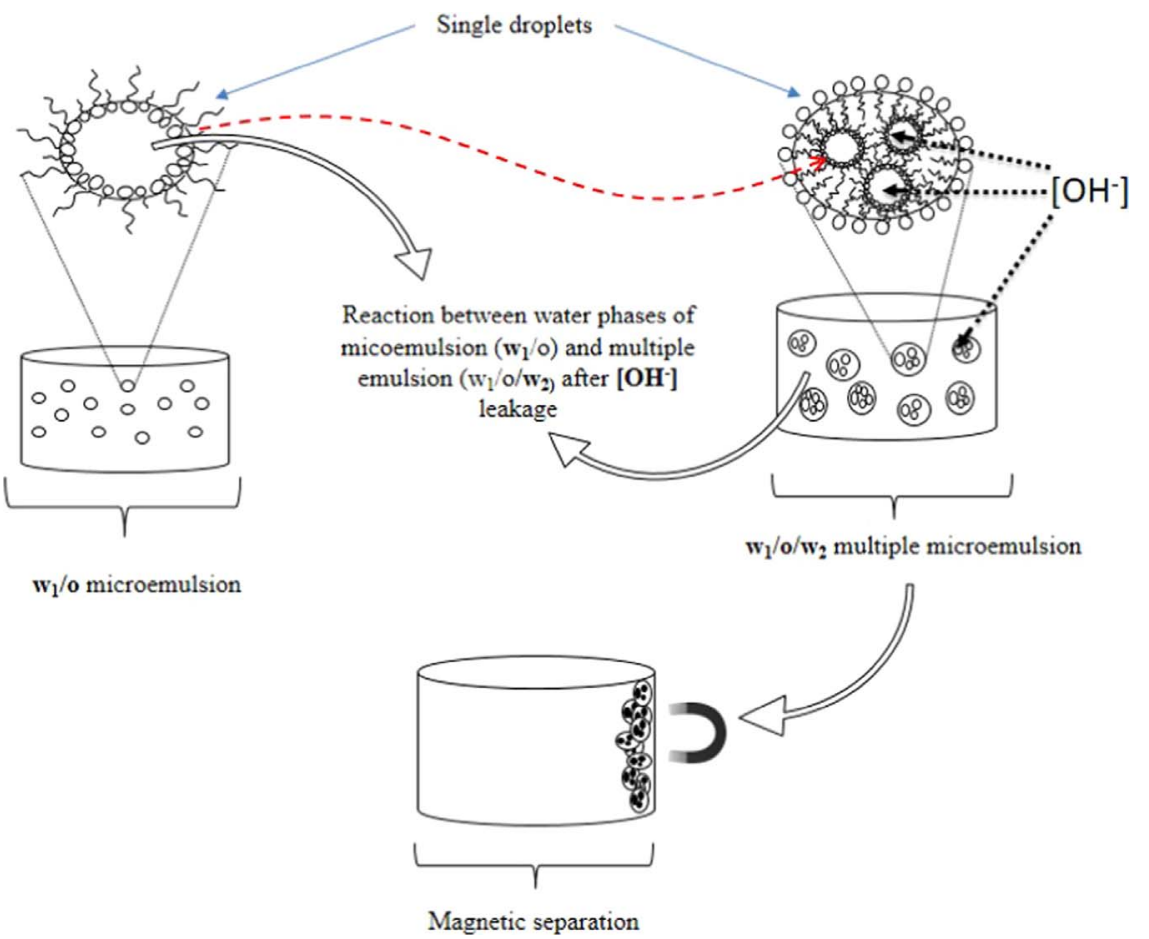

Fig. 1. Schematic illustration of synthesis and purification of MNPs by multiple emulsions method. 


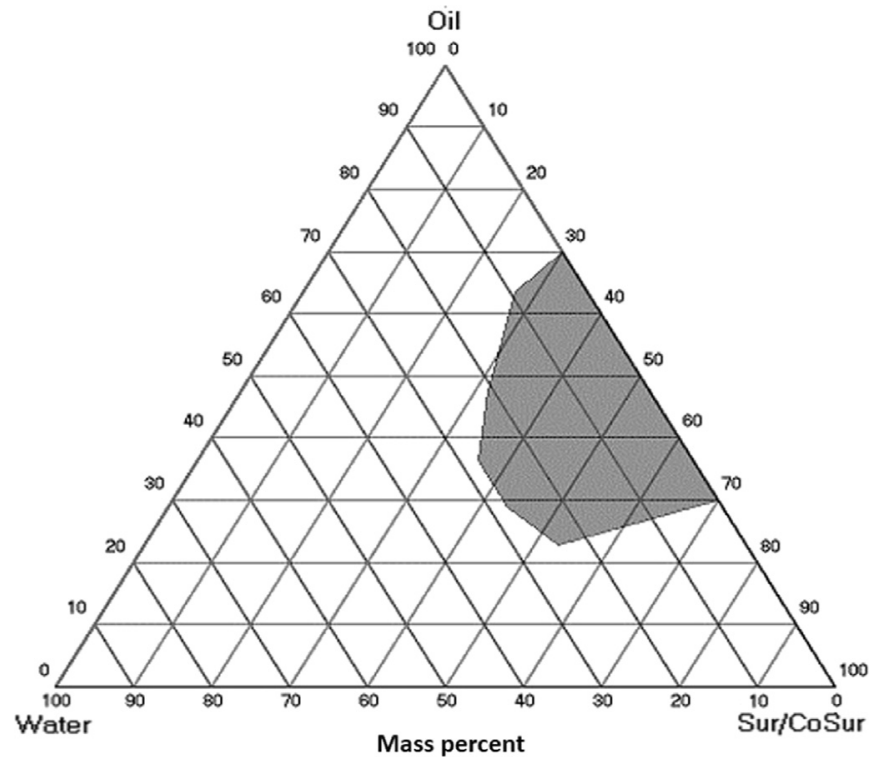

Fig. 2. Triangular phase diagram of $\mathbf{w}_{\mathbf{1}} / \mathbf{o}$ microemulsion formed with glyceryl monostearate as oil phase, Span 80 as non-ionic surfactant, ethanol as co-surfactant and $\mathrm{Fe}^{+2}$ and $\mathrm{Fe}^{+3}$ ionic solutions as water phase.

is co-precipitation method. Although the size of the MNPs obtained with this method can be small enough, there is no mechanism to control particle size and surface characteristics. The particle size distribution graph occupies a wide area [polydispersity index (PDI) is larger than 0.3] with MNP-CoP. There was insufficient homogeneity in size of MNPs. In the method that we developed, the iron compounds are in the form of droplets in limited volume reaction pools, within the inner water phase of multiple emulsions. Since the droplet size is limited by the reaction volume for production of MNPs, the particle sizes also become more controllable. For this purpose, firstly w/o microemulsions were prepared. The w/o microemulsion area was determined by the aid of triangle phase diagram and transparent water in oil systems were formed (Fig. 2). A formulation which has the largest volume of inner water phase was selected in transparent systems area of triangle phase diagram. Then, MNPs were obtained and characterized as described (Table 1).

When MNPs used without coating, they are cleared from body in a short time by the immune system. While their biocompatibility is a positive trait, they need to be coated with polymers or lipids in their applications as a delivery systems for drug or genes [3,16,28-31]. In addition to the coating process, it requires a second purification step to remove solvents [6]. In the system that we developed, MNPs synthesized in multiple emulsions appear in the form of solid lipid nanoparticles. Since the synthesis of MNPs spontaneously ensures the production in lipid-coated form there is no need an extra coating process as well as following purification steps. Therefore, a delivery system that is adequate to the specific purpose may also be produced by using another lipids used for the coating. In the system that we developed, a cationic lipid coating of the MNPs was ensured by the use of DDAB as in the oil phase of the microemulsion, realizing the cationic zeta potential value as a proof of cationic lipid coating after washing and magnetic separation processes [20,32,33]. Table 1 shows the particle size, PDI, and zeta potential of MNP-MuE and MNP-CoP. Zeta

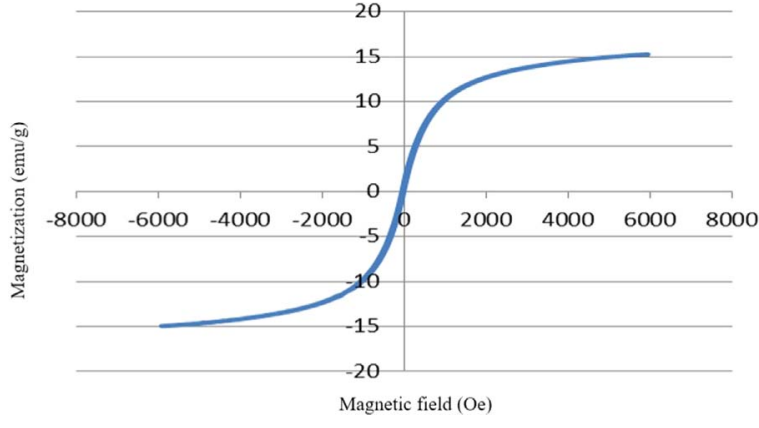

Fig. 3. Magnetic hysteresis of MNP-MuE.

potential measurements showed that negative values were determined when measuring of MNP-CoP, while positive values were found in MNPs which were obtained by multiple emulsion method because of cationic lipid coating in a single step.

The magnetic properties of MNP-MuE were analyzed by VSM. The magnetic properties such as saturation magnetization (Ms), remanent magnetization $(\mathrm{Mr})$ and coercivity $(\mathrm{Hc})$ were evaluated from the magnetization hysteresis of MNPs. As seen in Fig. 3, MNPs had a paramagnetic behavior and $\mathrm{Mr}$ and $\mathrm{Hc}$ values are approximately zero. Although saturation magnetization of MNP-CoP was higher than the coated samples that we prepared, coated MNPs had significant Ms values for magnetic targeting of drugs or nucleic acids $[11,28,29,34,35]$. Ms value was measured as $15-17 \mathrm{emu} \mathrm{g}^{-1}$ for lipid coated MNP-MuE while 2-3 times higher Ms values were reported on previous data for MNP-CoP $[6,18]$.

Representative SEM and TEM micrographs of MNP-MuE are shown in Fig. 4. These micrographs indicates that MNPs were covered with lipids and some agglomeration was also observed among MNPs. This may be caused by drying process on the copper grids for preparation to imaging instrument. SEM micrographs showed that black iron oxide core nanoparticles were covered with light grey colored lipid membrane (Fig. 4a) on the other hand the particles were more detectable in globular shape and narrow size distribution with TEM (Fig. 4b). Center of the spherical nanoparticles were darker than the walls of the spheres. TEM and SEM micrographs reflects particle size more directly than DLS method [36,37]. When micrographs were analyzed, particle size was measured as smaller than $30 \mathrm{~nm}$, which agrees well with the superparamagnetic character of the particles $[18,31,35]$.

VSM measurements indicated that MNPs synthesized by multiple emulsions are superparamagnetic. Raman spectroscopy studies were performed to identify the magnetic core material of MNP-MuE. Raman spectra measurements were usually performed in the literature with a He-Ne laser source giving an excitation wavelength of $633 \mathrm{~nm}$ for MNPs [38,39]. We also used $\mathrm{Ar}^{+}$laser source giving an excitation wavelength of $488 \mathrm{~nm}$ to reduce the high background fluorescence caused by lipid membrane and the Raman spectra were normalized with a software. Lipids yield large amount of fluorescence background. This fluorescence radiation might be coming from electron returning to ground state by emitting a light over time in addition to crystal vibrations (phonons). Fluorescence background, since it can effectively suppress the phonon spectrum, need to be subtracted from the data to obtain clean phonon spectrum. As a reference and to use for comparison nanoparticles without magnetic core (NP-Ø) were also evaluated

Table 1

Characterization results of MNP-MuE and MNP-CoP. SD stands for standard deviation.

\begin{tabular}{|c|c|c|c|}
\hline Formulation & Particle Size (nm) $( \pm$ SD) & PDI ( \pm SD) & Zeta Potantial $-\zeta(\mathrm{mV})( \pm \mathrm{SD})$ \\
\hline MNP-MuE & $139,9( \pm 2,902)$ & $0,160( \pm 0,023)$ & $41,1( \pm 1,641)$ \\
\hline MNP-CoP & $9,52( \pm 0,204)$ & $0,338( \pm 0,045)$ & $-25,9( \pm 0,656)$ \\
\hline
\end{tabular}


a.

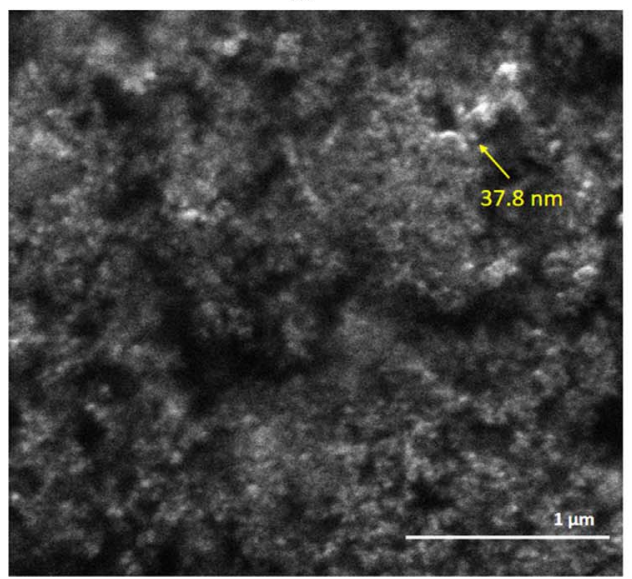

b.

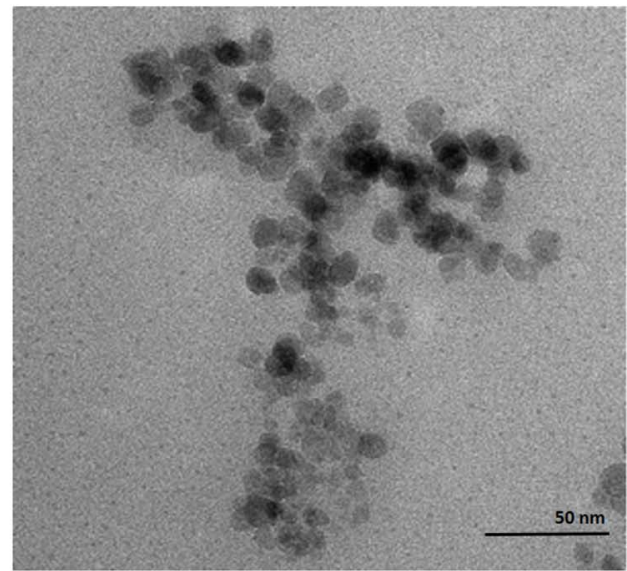

Fig. 4. SEM (a) and TEM (b) micrographs of MNP-MuE.

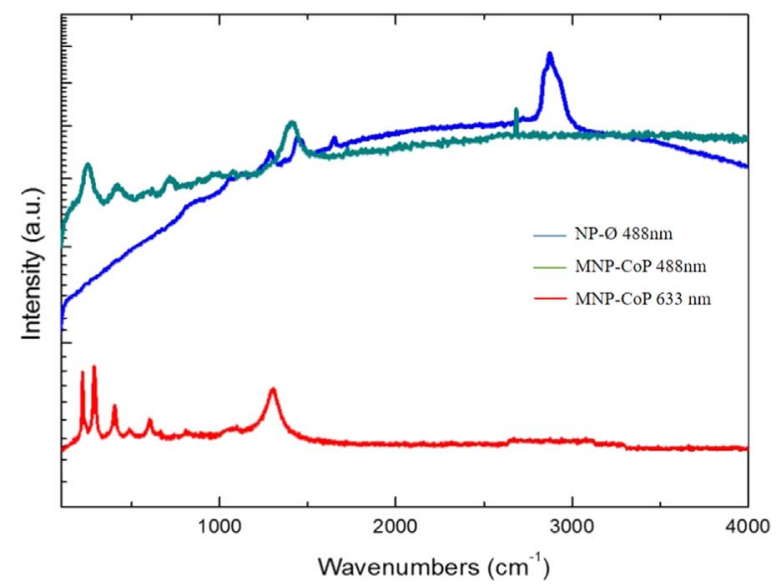

Fig. 5. Raman spectra of MNP-CoP and NP- $\varnothing$ (no magnetic core) with excitation wavelength of $633 \mathrm{~nm}$ and $488 \mathrm{~nm}$ with the grating of 150 groves $/ \mathrm{mm}$. Blue line represents NP-Ø $(488 \mathrm{~nm})$, green and red lines represent Raman spectra of MNP-CoP sample obtained with excitation wavelengths of $488 \mathrm{~nm}$ and $633 \mathrm{~nm}$, respectively. (For interpretation of the references to color in this figure legend, the reader is referred to the web version of this article.)

with Raman spectroscopy. These particles were only consist of the lipid component of the MNPs (Fig. 5).

In Fig. 5, Raman spectra of MNP-CoP were measured with excitation wavelength of $633 \mathrm{~nm}$ and $488 \mathrm{~nm}$ dispersed using a grating of 150 groves/mm. Magnetite has a poor Raman spectrum and high laser power induced phase transformation from magnetite to maghemite and haematite. Magnetite has a Raman shift peak at $668 \mathrm{~cm}^{-1}$, maghemite has strong peaks at $350 \mathrm{~cm}^{-1}, 500 \mathrm{~cm}^{-1}$ and $700 \mathrm{~cm}^{-1}$ while haematite has strong peaks at $225 \mathrm{~cm}^{-1}, 299 \mathrm{~cm}^{-1}$ and $412 \mathrm{~cm}^{-1}[39]$. From Fig. 5, Raman shift peaks of haematite ( $\alpha-$ $\left.\mathrm{Fe}_{2} \mathrm{O}_{3}\right)$ and maghemite $\left(\gamma-\mathrm{Fe}_{2} \mathrm{O}_{3}\right)$ can be observed. Therefore, it can be said that in our study, MNP-CoP are in $\alpha-\mathrm{Fe}_{2} \mathrm{O}_{3}$ structure which is more stable polymorph than $\gamma-\mathrm{Fe}_{2} \mathrm{O}_{3}$ or $\mathrm{Fe}_{3} \mathrm{O}_{4}$ forms. NP- $\varnothing$ has its own characteristic Raman spectrum which does not resembles that of iron oxide structures. No significant peaks were observed in the Raman spectrum in wavenumbers lower than $1000 \mathrm{~cm}^{-1}$.

Raman spectra measurements were also done for MNPs obtained by multiple emulsion method as well. MNP-MuE samples had also high background fluorescence caused by lipid membrane and they were normalized by excluding the fluorescence (Fig. 6). MNP-MuE and NP$\varnothing$ has strong peaks at $1450 \mathrm{~cm}^{-1}$ and $3000 \mathrm{~cm}^{-1}$ however MNP-MuE has also peaks between $500 \mathrm{~cm}^{-1}$ and $1000 \mathrm{~cm}^{-1}$ which is absent for NP-Ø particles (Fig. 5).

Peaks between $500 \mathrm{~cm}^{-1}$ and $1000 \mathrm{~cm}^{-1}$ are belong to magnetic

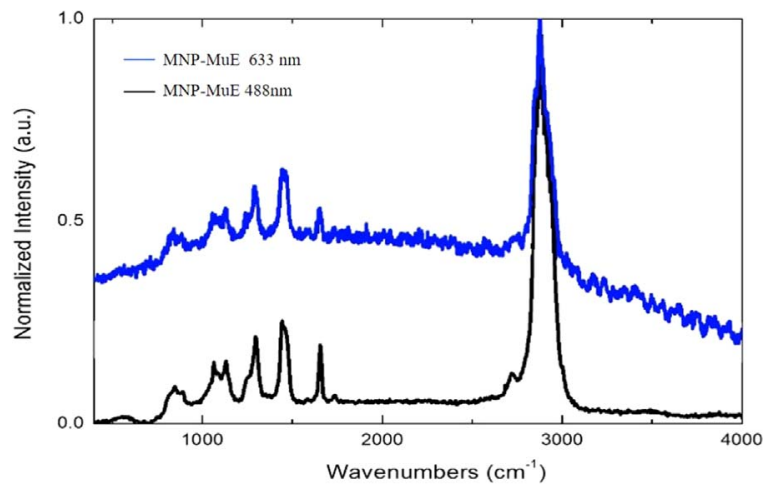

Fig. 6. Raman spectra of MNP-MuE collected with excitation wavelength of $633 \mathrm{~nm}$ (blue line) and $488 \mathrm{~nm}$ (black line) with 150 groves/mm grating. (For interpretation of the references to color in this figure legend, the reader is referred to the web version of this article.)

particles in the core of lipid membrane. There were no significant peaks under $500 \mathrm{~cm}^{-1}$ like maghemite of haematite. Lipid membrane coating may protect iron oxide compounds from oxidation or phase transformation caused by high laser power. MNP-MuE has more compatible peaks belongs to magnetite.

Lipid structures and iron oxide compounds have their own characteristic Raman Spectra and were not in resemblance to each other's spectrum. On the other hand, MNP-MuE and NP- $\varnothing$ has common peaks because of their lipid membrane; MNP-MuE and MNP-CoP has common peaks because of having peaks under $1000 \mathrm{~cm}^{-1}$. Magnetic particles are in the structure of $\alpha-\mathrm{Fe}_{2} \mathrm{O}_{3}$ for the co-precipitation method. External conditions such as $\mathrm{O}_{2}$ atmosphere and $\mathrm{pH}$ of the system may cause oxidation and $\mathrm{Fe}_{2} \mathrm{O}_{3}$ particles may have been synthesized instead of $\mathrm{Fe}_{3} \mathrm{O}_{4}$ particles [18,22]. In case of our method, Raman peaks showed that MNP-MuE has protective lipid cover on the superparamagnetic core material and structure of the magnetic core has peaks around $650 \mathrm{~cm}^{-1}$ to $700 \mathrm{~cm}^{-1}$ as in the magnetite structure.

Crystalline structure of MNPs were determined by XRD method and obtained data were illustrated in Fig. 7. Impurity was detected due to amorphous lipid structures but well-defined peaks were also detected. Fig. 7a shows the XRD pattern of MNP-MuE and graphic was normalized by subtracting the lipid signals. To use for comparison $\mathrm{NP}-\varnothing$ were also evaluated and compared with the MNP-MuE without normalizing the data in the Fig. $7 \mathrm{~b}$.

The XRD data in Fig. 7a shows the characteristic peaks of $\mathrm{Fe}_{3} \mathrm{O}_{4}$ and $\alpha-\mathrm{Fe}_{2} \mathrm{O}_{3}$ together. The line profile of peaks are both fitted to the structure of $\mathrm{Fe}_{3} \mathrm{O}_{4}$ for peaks 311, 222, 422; $\alpha-\mathrm{Fe}_{2} \mathrm{O}_{3}$ for peaks 104,110, 202. $\mathrm{FeO}$ was determined for the peak 101 [40]. The results of the XRD 
a.

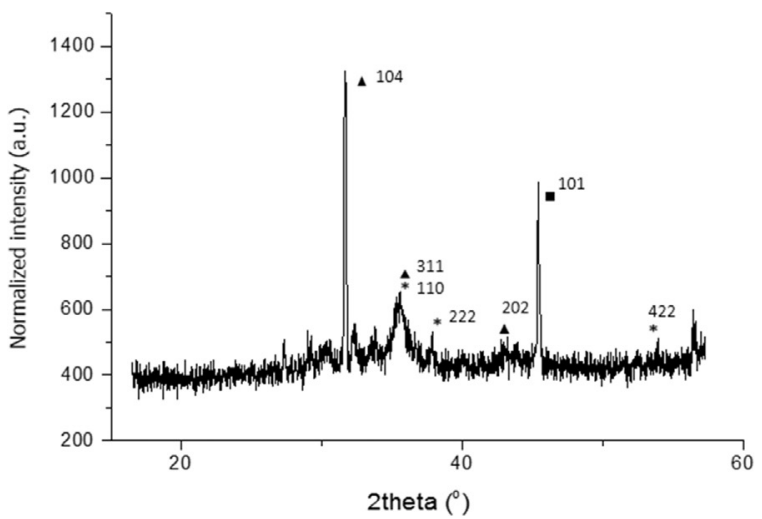

b.

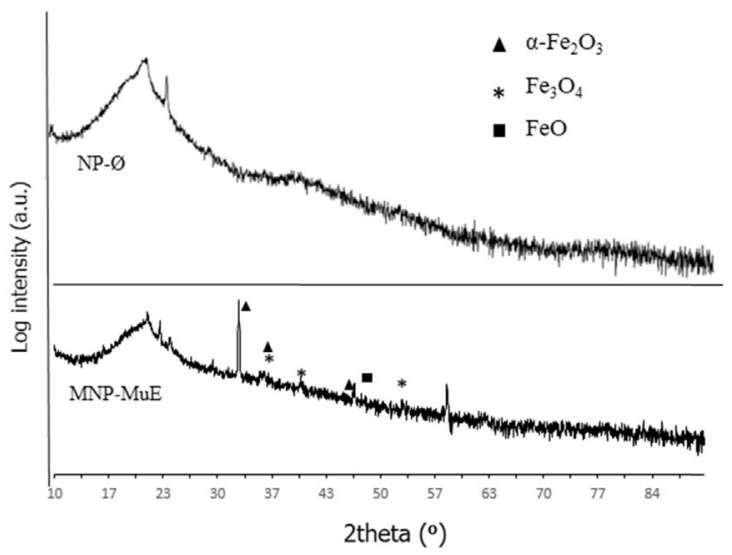

Fig. 7. X-ray diffraction patterns of MNP-MuE and NP- $\varnothing$, a. Normalized XRD pattern of MNP-MuE, b. XRD pattern comparison of unnormalized MNP-MuE and NP-Ø.

are agreed with the measurements of Raman Spectroscopy and superparamagnetic core material was found mainly in the form of $\mathrm{Fe}_{3} \mathrm{O}_{4}$ or its oxidized derivate $\alpha-\mathrm{Fe}_{2} \mathrm{O}_{3}$. Phase transformation from $\mathrm{Fe}_{3} \mathrm{O}_{4}$ to the $\alpha-\mathrm{Fe}_{2} \mathrm{O}_{3}$ may cause due to high laser application and drying process while sample preparation.

The XRD patterns of MNP-MuE and NP- $\varnothing$ were combined in the Fig. 7b. Patterns are almost similar. The only difference is the absence of the magnetic materials in the formulation of NP- $\varnothing$. There is no significant peaks were observed which resembles that of iron oxide structures. However MNP-MuE has common peaks that are identified in the normalized XRD pattern in Fig. 7a.

XPS technique was used to examine surface of the synthesized MNPs. Results were illustrated in the Fig. 8 and XPS mass percentages of the surface elements of MNPs are shown in the Table 2.

Surface ions can be detectable and distinguishable in XPS. From the bands of XPS spectra, the absorption sites and the interactions between magnetic materials and the lipids can be identified as well. A broad scan of all components of MNP-MuE, and expanded scans of iron and nitrogen ions were shown in the Fig. 8. Expanded photoelectron spectra of $\mathrm{Fe} 2 \mathrm{p}$ at 710.3 and $723.5 \mathrm{eV}$ are the characteristic peaks of iron oxides. Peaks are identified as Fe 2p3/2 and 2p1/2, respectively
Table 2

XPS mass percentages of the surface elements of MNPs.

\begin{tabular}{llll}
\hline & \multicolumn{1}{c}{ XPS (\%) } & & Calculated value (\%) \\
\cline { 2 - 3 } & MNP-MuE & NP-Ø & \\
\hline $\mathbf{C}$ & 79,75 & 91,71 & N/A \\
$\mathbf{N}$ & 1,24 & 1,58 & N/A \\
$\mathbf{O}$ & 16,97 & 6,71 & N/A \\
$\mathbf{F e}$ & 2,03 & 0 & $11,504(\mathrm{MNP}-\mathrm{MuE})$ \\
\hline
\end{tabular}

[41]. This shows the molecule is $\mathrm{Fe}_{3} \mathrm{O}_{4}$ and it is under oxidation state. This data is compatible to the Raman Spectra results and the XRD analysis. Both analysis identified magnetic core material in the form of $\mathrm{Fe}_{3} \mathrm{O}_{4}$ or its more stable and oxidized derivate $\alpha-\mathrm{Fe}_{2} \mathrm{O}_{3}$.

The spectra of N1s bands in Fig. 8 were also expanded. Band at $397.1 \mathrm{eV}$ is assigned to amino groups of the lipids in the formulation. The binding energy at $402.2 \mathrm{eV}$ was attributed to the cationic amino groups $\left(-\mathrm{N}^{+}\right)$that were reflects the presence of cationic lipid DDAB [42]. XPS spectra of the NP- $\varnothing$ was also examined. XPS mass percentages of the $\mathrm{C}, \mathrm{N}, \mathrm{O}$, and Fe were calculated in Table 2. The

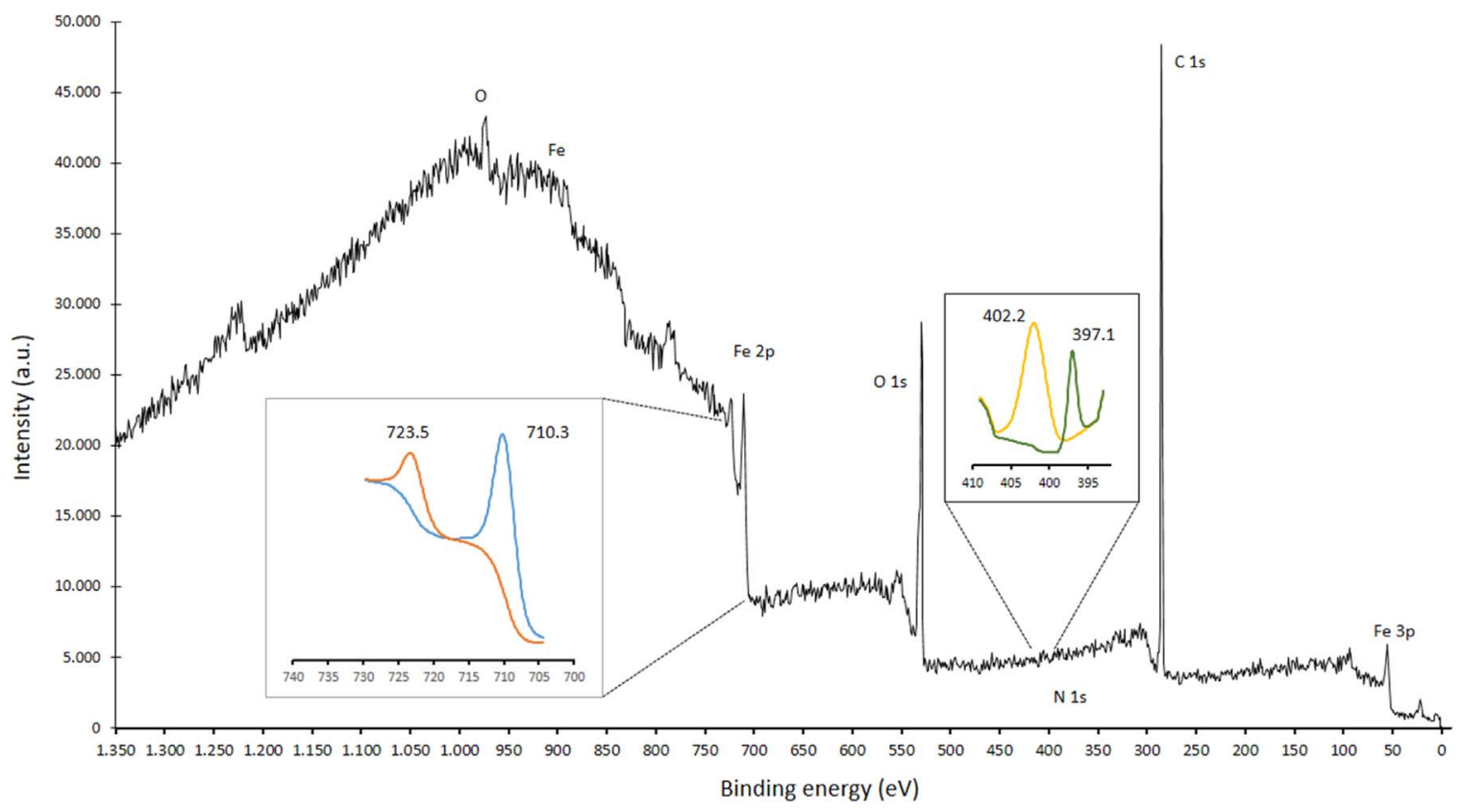

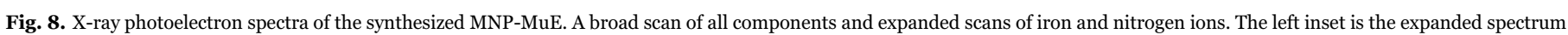
of $\mathrm{Fe} 2 \mathrm{p}$ and the right inset is the expanded spectrum of $\mathrm{N} 1 \mathrm{~s}$. 
mass percentage of the Fe in the MNP formulation was also calculated and placed in Table 2. MNP-MuE and NP- $\varnothing$ has similar nitrogen mass percentage due to cationic lipid DDAB. Fe was not found in NP- $\varnothing$ as it was expected. When we compare the XPS mass percentage of Fe on the surface of MNP-MuE to the calculated Fe in MNP-MuE, there is a 5.6 times more $\mathrm{Fe}$ calculated for MNP-MuE as a result of most of the magnetic materials were coated by lipid membrane as a structure of multiple emulsions [18].

\section{Conclusion}

The aim of this study was to obtain MNPs using multiple emulsions as microreactors. For this aim, $\left(1 \mathrm{M} \mathrm{Fe}^{+2}\right)$ and $\left(2 \mathrm{M} \mathrm{Fe}^{+3}\right)$ solutions were incorporated into the inner water phase of microemulsion and $2 \mathrm{~N}$ $\mathrm{NH}_{4} \mathrm{OH}$ was added in the outer phase of the multiple emulsion. $\left[\mathrm{OH}^{-}\right]$ ions leaked to the interior water phase of the multiple emulsion (w1/o/ w2) and reacted with $\mathrm{Fe}$ solutions. Therefore, magnetic iron oxide particles formed in the core of cationic solid lipid nanoparticle with optimal size and surface properties. These obtained MNP-MuE nanoparticles had similar magnetization hysteresis compared to those obtained by co-precipitation method and showed superparamagnetic characteristics. Particle size analysis were done on SEM and TEM micrographs and was measured smaller than $30 \mathrm{~nm}$ which was found compatible with superparamagnetic character. VSM measurements showed that MNP-MuE nanoparticles are superparamagnetic. Magnetic core materials structure was analyzed and it was found in the form of $\mathrm{Fe}_{3} \mathrm{O}_{4}$ or its more stable and oxidative derivate $\alpha-\mathrm{Fe}_{2} \mathrm{O}_{3}$ with Raman spectroscopy, XRD and XPS techniques.

Prepared MNP-MuE nanoparticles did not need any additional process for surface charge adjustments, they were already positively charged due to cationic lipid coating. The properties of MNPs such as size, zeta potential, and volume of magnetic core or lipid membrane could be adjusted according to the requirements of the desired delivery material. In this system MNPs were obtained by the use of a cationic lipid as the oil phase of the microemulsion, has potential to form complexes by its direct electrostatic interaction with DNA or any other anionic drug molecules and oil soluble compounds.

\section{Acknowledgements}

This work was supported by the Scientific and Technological Research Council of Turkey [TUBITAK SBAG 112S294, 2012]. In remembrance of our co-author Dr. Yusuf Selamet who passed away during the revision process of this paper.

\section{References}

[1] A. Kumar, P.K. Jena, S. Behera, R.F. Lockey, S. Mohapatra, S. Mohapatra, Multifunctional magnetic nanoparticles for targeted delivery,

Nanomed.Nanotechnol. Biol. Med. 6 (2010) 64-69. http://dx.doi.org/10.1016/ j.nano.2009.04.002.

[2] S.C. McBain, H.H.P. Yiu, J. Dobson, Magnetic nanoparticles for gene and drug delivery, Int. J. Nanomed. 3 (2008) 169-180. http://dx.doi.org/10.2147/ IJN.S1608.

[3] M. Arruebo, R. Fernández-Pacheco, M.R. Ibarra, J. Santamaría, Magnetic nanoparticles for drug delivery, Nano Today 2 (2007) 22-32. http://dx.doi.org/ 10.1016/S1748-0132(07)70084-1.

[4] J. Chomoucka, J. Drbohlavova, D. Huska, V. Adam, R. Kizek, J. Hubalek, Magnetic nanoparticles and targeted drug delivering, Pharmacol. Res. 62 (2010) 144-149. http://dx.doi.org/10.1016/j.phrs.2010.01.014.

[5] J. Dobson, Gene therapy progress and prospects: magnetic nanoparticle-based gene delivery, Gene Ther. 13 (2006) 283-287. http://dx.doi.org/10.1038/sj.gt.3302720.

[6] A.K. Gupta, M. Gupta, Synthesis and surface engineering of iron oxide nanoparticles for biomedical applications, Biomaterials 26 (2005) 3995-4021. http:// dx.doi.org/10.1016/j.biomaterials.2004.10.012.

[7] Z. Ma, H. Liu, Synthesis and surface modification of magnetic particles for application in biotechnology and biomedicine, China Particuol. 5 (2007) 1-10. http://dx.doi.org/10.1016/j.cpart.2006.11.001.

[8] K.F. Buckland, H.B. Gaspar, Gene and cell therapy for children-new medicines, new challenges?, Adv. Drug Deliv. Rev. 73 (2014) 162-169. http://dx.doi.org/ 10.1016/j.addr.2014.02.010.
[9] Y. Liu, P. Liu, Z. Su, F. Li, F. Wen, Attapulgite- $\mathrm{Fe}_{3} \mathrm{O}_{4}$ magnetic nanoparticles via coprecipitation technique, Appl. Surf. Sci. 255 (2008) 2020-2025. http://dx.doi.org/ 10.1016/j.apsusc.2008.06.193.

[10] V. Musat, O. Potecasu, R. Belea, P. Alexandru, Magnetic materials from coprecipitated ferrite nanoparticles, Mater. Sci. Eng. B Solid-State Mater. Adv. Technol. 167 (2010) 85-90. http://dx.doi.org/10.1016/j.mseb.2010.01.038.

[11] J.Y. Chen, Y.L. Liao, T.H. Wang, W.C. Lee, Transformation of Escherichia coli mediated by magnetic nanoparticles in pulsed magnetic field, Enzyme Microb. Technol. 39 (2006) 366-370. http://dx.doi.org/10.1016/j.enzmictec.2005.11.035.

[12] Z. Durmus, H. Kavas, A. Baykal, H. Sozeri, L. Alpsoy, S.Ü. Elik, et al., Synthesis and characterization of l-carnosine coated iron oxide nanoparticles, J. Alloy. Compd. 509 (2011) 2555-2561. http://dx.doi.org/10.1016/j.jallcom.2010.11.088.

[13] M.H. Liao, D.H. Chen, Characteristics of magnetic nanoparticles-bound YADH in water/AOT/isooctane microemulsions, J. Mol. Catal. B Enzym. 18 (2002) 81-87. http://dx.doi.org/10.1016/S1381-1177(02)00062-0.

[14] A. Bumajdad, S. Ali, A. Mathew, Characterization of iron hydroxide/oxide nanoparticles prepared in microemulsions stabilized with cationic/non-ionic surfactant mixtures, J. Colloid Interface Sci. 355 (2011) 282-292. http:// dx.doi.org/10.1016/j.jcis.2010.12.022.

[15] A. Košak, D. Makovec, M. Drofenik, A. Žnidaršič, In situ synthesis of magnetic MnZn-ferrite nanoparticles using reverse microemulsions, J. Magn. Magn. Mater. 272-276 (2004) 1542-1544. http://dx.doi.org/10.1016/j.jmmm.2003.12.252.

[16] J. Vidal-Vidal, J. Rivas, M.A. López-Quintela, Synthesis of monodisperse maghemite nanoparticles by the microemulsion method, Colloids Surf. A Physicochem. Eng. Asp. 288 (2006) 44-51. http://dx.doi.org/10.1016/j.colsurfa.2006.04.027.

[17] A.B. Chin, I.I. Yaacob, Synthesis and characterization of magnetic iron oxide nanoparticles via w/o microemulsion and Massart's procedure, J. Mater. Process. Technol. 191 (2007) 235-237. http://dx.doi.org/10.1016/j.jmatprotec.2007.03.011.

[18] J. Zhi, Y. Wang, Y. Lu, J. Ma, G. Luo, In situ preparation of magnetic chitosan/ $\mathrm{Fe}_{3} \mathrm{O}_{4}$ composite nanoparticles in tiny pools of water-in-oil microemulsion, React. Funct. Polym. 66 (2006) 1552-1558. http://dx.doi.org/10.1016/j.reactfunctpolym.2006.05.006.

[19] D.Kechrakos, Magnetic Nanoparticle Assemblies. Arxiv Prepr. arXiv09074417. 290. 〈http://arxiv.org/abs/0907.4417〉, pp. 33, 2009.

[20] J. Eastoe, M.J. Hollamby, L. Hudson, Recent advances in nanoparticle synthesis with reversed micelles, Adv. Colloid Interface Sci. 128-130 (2006) 5-15. http:// dx.doi.org/10.1016/j.cis.2006.11.009.

[21] D.S. Mathew, R.S. Juang, An overview of the structure and magnetism of spinel ferrite nanoparticles and their synthesis in microemulsions, Chem. Eng. J. 129 (2007) 51-65. http://dx.doi.org/10.1016/j.cej.2006.11.001.

[22] T. Ozkaya, A. Baykal, M.S. Toprak, Y. Koseoğlu, Z. Durmus, Reflux synthesis of Co3O4 nanoparticles and its magnetic characterization, J. Magn. Magn. Mater. 321 (2009) 2145-2149. http://dx.doi.org/10.1016/j.jmmm.2009.01.003.

[23] J. Li, X. Wei, Y. Yuan, Synthesis of magnetic nanoparticles composed by Prussian blue and glucose oxidase for preparing highly sensitive and selective glucose biosensor, Sens. Actuators B Chem. 139 (2009) 400-406. http://dx.doi.org/ 10.1016/j.snb.2009.03.004.

[24] T. Schmidts, D. Dobler, A. Guldan, N. Paulus, F. Runkel, Colloids and surfaces A: physicochemical and engineering aspects multiple W/O/W emulsions-using the required HLB for emulsifier evaluation, Colloids Surf. A Physicochem. Eng. Asp. 372 (2010) 48-54. http://dx.doi.org/10.1016/j.colsurfa.2010.09.025.

[25] E. Ugazio, R. Cavalli, M.R. Gasco, Incorporation of cyclosporin A in solid lipid nanoparticles (SLN), Int. J. Pharm. 241 (2002) 341-344. http://dx.doi.org/ 10.1016/S0378-5173(02)00268-5.

[26] E. Marengo, R. Cavalli, O. Caputo, L. Rodriguez, M.R. Gasco, Scale-up of the preparation process of solid lipid nanospheres. Part I, Int. J. Pharm. 205 (2000) 3-13. http://dx.doi.org/10.1016/S0378-5173(00)00471-3.

[27] L. Serpe, M.G. Catalano, R. Cavalli, E. Ugazio, O. Bosco, R. Canaparo, et al., Cytotoxicity of anticancer drugs incorporated in solid lipid nanoparticles on HT-29 colorectal cancer cell line, Eur. J. Pharm. Biopharm. 58 (2004) 673-680. http:// dx.doi.org/10.1016/j.ejpb.2004.03.026.

[28] E. Tomb Acz, R. Turcu, V. Socoliuc, L.V. Ek As, Magnetic iron oxide nanoparticles: recent trends in design and synthesis of magnetoresponsive nanosystems, Biochem Biophys. Res. Commun. (2015). http://dx.doi.org/10.1016/j.bbrc.2015.08.030.

[29] S.P. Gubin, Y.A. Koksharov, G.B. Khomutov, G.Y. Yurkov, Magnetic nanoparticles: preparation methods, structure and properties, Usp. Khim. 74 (2005) 539-574. http://dx.doi.org/10.1070/RC2005v074n06ABEH000897.

[30] O. Veiseh, J.W. Gunn, M. Zhang, Design and fabrication of magnetic nanoparticles for targeted drug delivery and imaging, Adv. Drug Deliv. Rev. 62 (2010) 284-304. http://dx.doi.org/10.1016/j.addr.2009.11.002.

[31] M. Mahmoudi, S. Sant, B. Wang, S. Laurent, T. Sen, Superparamagnetic iron oxide nanoparticles (SPIONs): development, surface modification and applications in chemotherapy, Adv. Drug Deliv. Rev. 63 (2011) 24-46. http://dx.doi.org/10.1016/ j.addr.2010.05.006.

[32] X. Pan, J. Guan, J.W. Yoo, A.J. Epstein, L.J. Lee, R.J. Lee, Cationic lipid-coated magnetic nanoparticles associated with transferrin for gene delivery, Int. J. Pharm. 358 (2008) 263-270. http://dx.doi.org/10.1016/j.ijpharm.2008.02.020.

[33] E. Vighi, B. Ruozi, M. Montanari, R. Battini, E. Leo, pDNA condensation capacity and in vitro gene delivery properties of cationic solid lipid nanoparticles, Int. J. Pharm. 389 (2010) 254-261. http://dx.doi.org/10.1016/j.ijpharm.2010.01.030.

[34] C. Sun, J.S.H. Lee, M. Zhang, Magnetic nanoparticles in MR imaging and drug delivery, Adv. Drug Deliv. Rev. 60 (2008) 1252-1265. http://dx.doi.org/10.1016/ j.addr.2008.03.018.

[35] G. Utkan, F. Sayar, P. Batat, S. Ide, M. Kriechbaum, E. Pişkin, Synthesis and characterization of nanomagnetite particles and their polymer coated forms, J. 
Colloid Interface Sci. 353 (2011) 372-379. http://dx.doi.org/10.1016/ j.jcis.2010.09.081.

[36] D. Lee, G. Cho, H.M. Lim, D.S. Kim, C. Kim, S. Lee, Comparisons of particle size measurement method for colloidal silica, J. Ceram. Process. Res. 14 (2013) 274-278.

[37] J. Lim, S. Yeap, H. Che, S. Low, Characterization of magnetic nanoparticle by dynamic light scattering, Nanoscale Res. Lett. 8 (2013) 381. http://dx.doi.org/ 10.1186/1556-276X-8-381.

[38] S. Haracz, M. Hilgendorff, J.D. Rybka, M. Giersig, Effect of surfactant for magnetic properties of iron oxide nanoparticles, Nucl. Instrum. Methods Phys. Res. Sect. B Beam Interact. Mater. At. 364 (2015) 120-126. http://dx.doi.org/10.1016/ j.nimb.2015.08.035.

[39] J.-F. Lu, C.-J. Tsai, Hydrothermal phase transformation of haematite to magnetite,
Nanoscale Res. Lett. 9 (2014) 230. http://dx.doi.org/10.1186/1556-276X-9-230.

[40] R. Han, W. Li, W. Pan, M. Zhu, D. Zhou, F. Li, 1D Magnetic materials of $\mathrm{Fe}_{3} \mathrm{O}_{4}$ and Fe with high performance of microwave absorption fabricated by electrospinning method, Sci. Rep. 4 (2014) 7493. http://dx.doi.org/10.1038/srep07493.

[41] G. Unsoy, S. Yalcin, R. Khodadust, G. Gunduz, U. Gunduz, Synthesis optimization and characterization of chitosan coated iron oxide nanoparticles produced for biomedical applications, J. Nanopart. Res. 14 (2012) 964-977. http://dx.doi.org/ 10.1007/s11051-012-0964-8.

[42] S. Demirci, T. Caykara, RAFT-mediated synthesis of cationic poly[(ar-vinylbenzyl) trimethylammonium chloride] brushes for quantitative DNA immobilization, Mater. Sci. Eng. C 33 (2013) 111-120. http://dx.doi.org/10.1016/ j.msec.2012.08.015. 